\title{
USO TÓPICO DE SOLUÇÃO DE SULFATO DE MORFINA 1\% EM OLHOS SAUDÁVEIS DE CÃES
}

\author{
(Topical 1\% morphine sulfate solution in intact cornea of dogs)
}

\author{
Michele Lopes Izar ${ }^{1}$, Paola Stramandinoli Branco ${ }^{1}$, Daniel Zannin ${ }^{1}$, Ricardo Guilherme \\ D'Otaviano de Castro Vilani ${ }^{1}$
}

1Departamento de Medicina Veterinária. Setor de Ciências Agrárias. Universidade Federal do Paraná.

*Correspondência: vilani@ufpr.br

RESUMO: A córnea é um dos tecidos mais ricamente inervados do organismo. Receptores opioides já foram detectados na córnea, sendo o uso tópico de opioides uma alternativa analgésica no tratamento de úlceras de córnea, sem prejudicar a cicatrização. Este trabalho teve como objetivo avaliar a sensibilidade corneana do uso de solução de sulfato de morfina $1 \%$ na córnea íntegra de cães. Dez cães sem lesão ocular foram tratados com uma gota de solução fisiológica $0,9 \%$ no olho direito (GC), e uma gota de solução de sulfato de morfina $1 \% \mathrm{com} \circ \mathrm{pH}$ corrigido para 7,2 no olho esquerdo (GM). Foram realizados os exames de tonometria, estesiometria, teste lacrimal de Schirmer, medição do diâmetro pupilar e avaliados a intensidade da hiperemia conjuntival e presença de blefaroespasmo com e sem fonte de luz. As avaliações ocorreram antes das aplicações e nos momentos 10, 20, 30, 60 e 240 minutos após a instilação do último colírio. Foi realizada análise de variância (ANOVA) para os testes paramétricos, com comparação das médias pelo teste de Tukey-Kramer. A hiperemia e blefaroespasmo foram avaliados pelo teste de qui-quadrado. A hiperemia conjuntival observada no grupo GM foi significativamente maior (7/10) que a do grupo GC, que não apresentou hiperemia. $(P<0,05)$. Dois olhos do $\mathrm{GM}$ apresentaram blefaroespasmo na presença de fonte de luz aos 10 minutos. Não houve diferença estatística entre os valores de sensibilidade corneana, diâmetro pupilar, e produção lacrimal. A pressão intraocular foi menor no grupo GM no momento 240 comparado ao grupo $\mathrm{GC}(P<0,05)$. A solução de sulfato de morfina $1 \%$ não promove efeito analgésico quando administrada em córnea íntegra de cães e está associada a efeitos irritativos no olho e anexos logo após a instilação.

Palavras-chave: córnea, úlcera, opioide, analgesia

ABSTRACT: Cornea is one of the most highly innervated tissues in the organism. Opioid receptors have already been detected in cornea; so the topical use of opioids is presented as an analgesic alternative in treatment of ulcerated corneas, with no damage in cicatrization. This research aimed to evaluate the corneal sensitivity of the $1 \%$ morphine sulfate solution in the intact cornea of dogs. Ten dogs with no ocular lesions were treated with one drop of saline solution on right eye (GC), and one drop of $1 \%$ morphine sulfate solution with the $\mathrm{pH}$ corrected for 7.2 on left eye (GM). The parameters evaluated were: tonometry, esthesiometry, Schirmer lacrimation test, pupil diameter and the presence of conjunctival hyperemia and blepharospasm with and without light source. The evaluations happened before collyrium instillation and 10, 20, 30, 60 and 240 minutes after it. It was performed 
variance analysis (ANOVA) for the parametric tests, comparing the means by the Tukey-Kramer test. Hyperemia and blepharospasm were evaluated by the chisquare test. The conjunctival hyperemia observed in the GM group was significantly higher $(7 / 10)$ than in the CG group, which did not present hyperemia $(P<0.05)$. Two eyes from GM showed blepharospasm with light source at 10 minutes. There were no differences in corneal sensibility, pupil diameter and Schirmer lacrimation test. The intraocular pressure was lower in the GM group compared to the GC group at 240 minutes. Topical administration of $1 \%$ morphine sulfate solution does not cause analgesia in intact cornea and promote irritation in eye and annex after instillation.

Key Words: cornea, ulcer, opioid, analgesia

\section{INTRODUÇÃO}

A córnea é um dos tecidos mais ricamente inervados do organismo. Recebe densa inervação sensorial do nervo trigêmio e modesta inervação simpática do gânglio cervical superior, com importantes efeitos neuromodulatórios na cicatrização de lesões (Rozsa e Beuerman, 1982; Marfurt et al., 2001).

A inervação corneana se concentra na parte externa da córnea (epitélio e extroma superior). O plexo nervoso subepitelial surge dos nervos presentes no estroma e são nervos altamente anastomóticos localizados no estroma superficial, imediatamente abaixo da interface estroma-epitélio (Kafarnik et al., 2008).

A úlcera de córnea se caracteriza por perda de epitélio corneano e ativação de fibroblastos presentes no estroma, o que leva a uma edemaciação e migração de células inflamatórias com subsequente perda da integridade $\mathrm{e}$ transparência da córnea (Garg e Rao, 1999; Prado et al., 2006).

A ceratite ulcerativa é uma das doenças oculares mais comuns e importantes em animais domésticos, principalmente nos cães, tendo origem usualmente traumática e rápida contaminação bacteriana. Leva à opacidade corneana, causando dor e baixa de acuidade visual nas diferentes espécies, inclusive nos seres humanos
(Gelatt, 2003a; Gelatt, 2003b; Ollivier, 2003; Maidana et al., 2005; Slatter, 2005; Prado et al., 2006; Werner et al., 2008a; Werner et al., 2008b; Keay et al., 2009). O tratamento da ceratite ulcerativa inclui, além de erradicar a infecção, reduzir ou cessar a lise corneana, minimizar cicatrizes e controlar a dor (Ollivier, 2003; Iwamoto et al., 2017). O uso de anti-inflamatórios esteroidais ou não esteroidais tópicos, muito utilizados no tratamento da dor em cirurgias oftálmicas, estão associados a um prejuízo na cicatrização da córnea devido à sua ação sob a cascata do ácido aracdônico $\mathrm{e}$ as enzimas COX respectivamente. Devido a isto, ocorre uma diminuição da migração de ceratócitos, ativação de proteases e colagenólise (Hendrix et al., 2002; Werner et al., 2008a; Werner et al., 2008b; Iwamoto et al., 2017).

Os opioides são rotineiramente utilizados por via parenteral para promover analgesia. Além do efeito de modulação central da dor, também promovem ação analgésica quando aplicadas em tecidos e neurônios periféricos (Stiles et al., 2003). Outra função dos opioides está na homeostase e renovação celular do epitélio corneano, tendo papel importante na reparação de lesões corneanas (Zagon et al., 1998). Foram identificados receptores opioides $\mu$ e $\delta$ em córnea saudável de cães observando subjetivamente uma maior 
prevalência de receptores $\delta$ em grandes axônios no estroma anterior, bem como em pequenas fibras no estroma subepitelial, e terminações nervosas dentro do epitélio corneano. Receptores $\mu$ foram observados em pequena quantidade, estando localizados principalmente no estroma anterior e subepitelial (Stiles et al., 2003). Células nervosas contendo receptores $\delta$-opioide também foram identificadas na região subepitelial, pericorneana e nas camadas superficiais do epitélio corneano e no limbo de ratos. (Wenk e Honda, 1999).

O presente estudo teve por objetivo avaliar os efeitos analgésicos e adversos da solução de sulfato de morfina $1 \%$ administrada em cães com córneas íntegras.

\section{MATERIAL E METODOS}

Este estudo foi aprovado pelo Comitê de Ética para o Uso de Animais do Setor de Ciências Agrárias da Universidade Federal do Paraná (protocolo 012/2010 CEUA-SCA UFPR).

Dez cães de raças, idades e tamanhos diferentes, sem qualquer histórico clínico de doenças sistêmicas ou oftálmicas recentes e com córneas íntegras foram utilizados.

Todos os animais tiveram seus bulbos oculares submetidos aos exames oftálmicos de rotina, sendo estes: a inspeção ocular direta e com auxílio de fonte de luz, a estesiometria (Estesiometro de Cochet-Bonnet Luneau Ophtalmologie, Paris, França), a tonometria com o tonômetro de Shiotz (Tonômetro de Shiotz - Miltex, Nova Jersey, EUA), o Teste Lacrimal de Schirmer - TLS (Teste de Schirmer Ophthalmos, São Paulo, Brasil) e a paquimetria do diâmetro pupilar (Paquímetro Digital Vonder - São Paulo, Brasil). Os parâmetros avaliados foram a presença de blefarospasmo e hiperemia ocular. As avaliações foram feitas antes das administrações dos colírios e nos momentos 10, 20, 30, 60 e 240 minutos após a instilação do último colírio, com exceção do TLS que foi realizado antes da administração dos colírios e 30 minutos após. Todos os animais foram submetidos ao mesmo protocolo, que consistiu da instilação de uma gota da solução de sulfato de morfina $1 \%$ no bulbo ocular esquerdo (grupo morfina - GM) e uma gota de solução fisiológica $0,9 \%$ no bulbo ocular direito (grupo controle - GC). O avaliador, por sua vez, não conhecia a que grupo pertencia cada olho. Em todos os olhos foi administrada uma gota de colírio de tobramicina 0,3\% ${ }^{1}, 15$ minutos antes do tratamento.

A solução de morfina foi preparada a partir de uma solução comercial de morfina $1 \%{ }^{2}$ sem conservantes, com excipiente constituído de cloreto de sódio, ácido clorídrico e água estéril e com o pH ajustado para 7,2. Foi adicionado solução tampão de hidróxido de sódio e o pH continuou sendo controlado por meio de $\mathrm{pHmetro}^{3}$, de 12 a 18 horas antes da aplicação.

Para os dados paramétricos foi utilizado tratamento estatístico pelo Teste-t por meio de programa StatView 5.0.1 (SAS Institute Inc., NC, USA). Os dados não paramétricos como a hiperemia conjuntival e o blefaroespasmo com e sem fonte de luz foram comparados pelo teste de quiquadrado.

\section{RESULTADOS}

Foi observada hiperemia em 7 dos 10 olhos do GM após 10 minutos da aplicação $(P<0,05)$ e em 4 olhos após

\footnotetext{
${ }^{1}$ Medicamento Genérico Aché Biossintética Genéricos. São Paulo, Brasil

2 Dimorf® ampola de $2 \mathrm{ml} 10 \mathrm{mg} / \mathrm{ml}$ Cristália

Produtos químicos farmacêuticos LTDA., São

Paulo, Brasil

${ }^{3}$ pHmetro PG 1800, Gehaka - São Paulo, Brasil
} 
20 minutos, 3 com 30 minutos, 2 com 60 minutos e um olho persistiu com hiperemia até a última avaliação aos 240 minutos. Não foi observada hiperemia nos olhos do GC. Dois olhos do GM apresentaram blefaroespasmo na presença de fonte de luz aos 10 minutos, resultados não observados no GC e nas avaliações seguintes.

Não foram encontradas diferenças estatísticas das médias de estesiometria (Figura 1A), diâmetro pupilar (Figura 1B) e produção lacrimal (Figura $1 \mathrm{C}$ ) $(P=0,05)$. Foi observada diferença estatística para a pressão intraocular entre os grupos no momento 240 minutos $(P<0,05)$, porém isto não ocorreu em nenhum outro momento (Figura 1D).

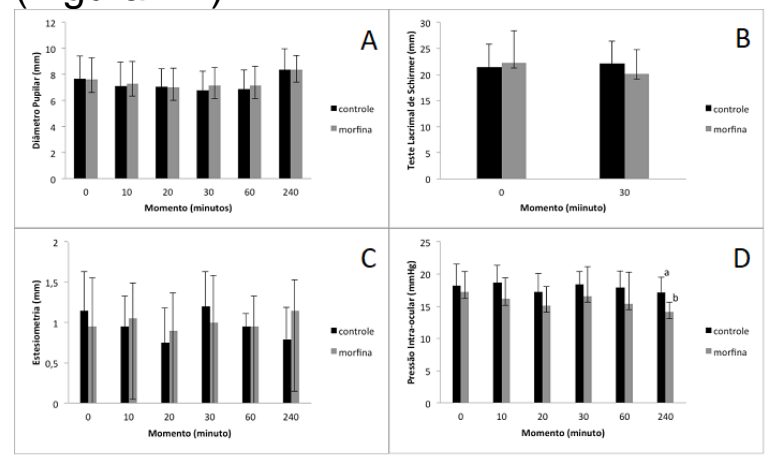

Figura 1- Valores para diâmetro pupilar (A), teste lacrimal de Schirmer (B), sensibilidade corneana (C) e pressão intraocular (D) para cães tratados com cloreto de sódio 0,9\% (GC); sulfato de morfina 1\% (GM). Nota: letras diferentes $(a, b)$ representam valores diferentes $(P<0,05)$ entre $G M$ e GC.

\section{DISCUSSÃO}

Pesquisas com uso de solução de morfina tópica para alivio da dor em pacientes com úlcera de córnea ainda são relativamente escassos tanto na literatura humana como na veterinária. A solução tópica de morfina a $0,5 \%$ e $1 \%$ possui efeito analgésico na córnea ulcerada de coelhos, cães e seres humanos (Peyman et al., 1994, Stiles et al., 2003). O uso de morfina tópica em coelhos com lesão de córnea superficial induzida demonstrou uma cicatrização levemente superior ao tratamento com o diclofenaco e solução fisiológica (Izar, 2012).

Receptores opioides, assim como neuropeptídios e outras proteínas, são sintetizados em gânglios da raiz dorsal, sendo carreados por via axonal para terminais centrais e periféricos (Stein et al., 2001). A expressão destes receptores opioides pode ser modulada por reação inflamatória próxima aos terminais de neurônios aferentes primários (Stein et al., 2001). O transporte axonal do receptor opioide é aumentado devido à liberação de interleucina $1 \beta$ (IL-1 $\beta$ ), levando a um aumento na eficácia do agonista em nervos periféricos (Stiles et al., 2003). Quando não há lesão ocular, não existe esse estímulo para expressão dos receptores e, portanto, não se observa efeito analgésico (Peyman, et. al., 1994; Wenk, et. al., 2003), como observado em córnea íntegra no presente estudo.

A irritação ocular, caracterizada pela hiperemia, blefaroespasmo e fotofobia, observada nos nossos animais após a instilação da solução de sulfato de morfina $1 \%$, pode ser um efeito adverso tópico, mesmo após a neutralização do $\mathrm{pH}$. A irritação ocular observada pode ser explicada pela liberação de histamina, ou pela variação no $\mathrm{pH}$ decorrente do veículo utilizado nas apresentações parenterais da morfina (Trescot et al., 2008). Outros medicamentos, como o colírio de proparacaína e principalmente o de tetracaína causam de leve a moderada hiperemia de conjuntiva e blefaroespasmo logo após a instilação em cães e coelhos, sendo que esta se tornava novamente normocrômica pouco tempo depois (Parchen et al., 2011; Amaral, 2013;). Apesar desse efeito adverso ser uma desvantagem do uso tópico da morfina na córnea, não é diretamente uma contraindicação do seu uso em pacientes com úlcera de córnea onde a morfina tem ação analgésica quando utilizada topicamente. 
A avaliação comportamental de desconforto e dor ocular, incluindo blefaroespasmo e hiperemia, deve ser associada à resposta direta ao estímulo doloroso corneano provocado pelo estesiômetro de Cochet-Bonnet quando se pretende avaliar o efeito álgico no bulbo e anexos, uma vez que o objetivo do estesiômetro é avaliar exclusivamente a reação de dor na córnea.

\section{CONCLUSÃO}

Conclui-se com este estudo que a solução de sulfato de morfina $1 \%$ não promove efeito analgésico quando administrada em córnea íntegra de cães e está associada a efeitos irritativos no olho e anexos logo após a instilação.

\section{REFERENCIAS}

AMARAL, A.V.C.; CHAVES, N.S.T.; SILVA, L.A.F. et al. Estudo clínico e histológico das pálpebras, conjuntiva e córnea hígidas submetidas a tratamento tópico com soluções anestésicas em coelhos. Arquivos Brasileiros de Medicina Veterinária e Zootecnia. v.65, n.1, p.67-74, 2013.

KAFARNIK, C.; FRITSCHE, J.; RESSE, $S$. Corneal innervation in mesocephalic and brachycephalic dogs and cats: assessment using in vivo confocal microscopy. Veterinary Ophthalmology. v.6, p. 363-367, 2008.

GARG, P.; RAO, N. G.; Corneal Ulcer: Diagnosis and Management. Community Eye Health. v.12. n.30, p. 21-23, 1999.

GELATT, K.N. Doenças e cirurgia da córnea e esclera do cão. In: GELATT, K.N. Manual de Oftalmologia Veterinária. 1.ed. Editora Manole Ltda: São Paulo, 2003.

GELATT, K.N. Glaucoma do cão. In: GELATT, K.N. Manual de Oftalmologia
Veterinária. 1.ed. Editora Manole Ltda: São Paulo, 2003.

HENDRIX, D.V.H.; WARD, D.A.; BARNHILL, M.A. Effects of antiinflammatory drugs and preservatives on morphologic characteristics and migration of canine corneal epithelial cells in tissue culture. Veterinary Ophthalmology. v.5, p.127- 135, 2002.

IZAR, M.L. Estudo imuno-histoquímico de receptores opioides corneais e avaliação do uso tópico de solução de sulfato de morfina em pacientes com ceratite ulcerativa. 2012. Curitiba, $49 f$. Dissertação (Mestrado em Ciências Veterinárias) - Curso de Pós-Graduação em Ciências Veterinárias, Universidade Federal do Paraná.

KEAY, L.; EDWARDS, K.; STAPLETON, F. Signs, symptoms, and comorbidities in contact lens - related microbial keratitis.

Optometry and Vision Science. v.86, p.803-809, 2009.

MAIDANA, E.; GONZÁLEZ, R.; MELO JÚNIOR, L.A.S. et al. Ceratite infecciosa em crianças: estudo microbiológico e epidemiológico em um hospital universitário de Assunção - Paraguai. Arquivo Brasileiro de Oftalmologia. v.68, p.828-832, 2005.

MARFURT, C.F.; MURPHY, C.J.; FLORCZAK, J.L. Morphology and neurochemistry of canine corneal innervation. Investigative Ophthalmology \& Visual Science. v. 42, p.2244-2251, 2001.

OLLIVIER, F.J. Bacterial corneal diseases in dogs and cats. Clinical Techniques in Small Animal Practice. v.18, p.193-198, 2003.

PARCHEN, H.D.; IZAR, M.I.; BRANCO, P.S. et al. Ophthalmic and anesthetic evaluation of topical $1 \%$ tetracaine and $0,5 \%$ proparacaine in dogs. Arquivo Brasileiro de Medicina Veterinária e Zootecnia. v.63, n. 6, p.1337-1344, 2011. 
PEYMAN, G.A.; RAHIMY, M.H.; FERNANDES, M.L. Effects of morphine on corneal sensitivity and epithelial wound healing: implications for topical ophthalmic analgesia. British Journal of Ophthalmology. v.78, p.138-141, 1994.

PRADO, M.R.; BRITO, E.H.S.; GIRÃO, M.D. et al. Identification and antimicrobial susceptibility of bacterial isolated from corneal ulcers of dogs. Arquivo Brasileiro de Medicina Veterinária e Zootecnia. v.58, p.1024-1029, 2006.

ROZSA, A.J.; BEUERMAN, R.W. Density and organization of free nerve endings in the corneal epithelium of the rabbit. Pain. v.14, p.105-120, 1982.

IWAMOTO, S.; KOGA, T.; OGBA, M.; OKUNO, T.; KOIKE, M.; MURAKAMI, A.; MATSUDA, A.; YOKOMIZO, T. Nonsteroidal anti-inflammatory drug delas corneal wound healing by recuding production of 12hydroxyheptadecatrienoic acid, a ligand for leukotriene $B_{4}$ receptor 2. Scientific Reports. v. 7 , p. 1-10, 2017.

\section{SLATTER, D. Fundamentos de} Oftalmologia Veterinária. 3.ed. Editora Roca, 2005.

Stein C.; MACHELSKA, H.; SCHÄFER, $M$. Peripheral analgesic and antiinflamatory effects of opioids. Zeitschrift Fur Rheumatologie. v.60, p. 416-424, 2001.

STILES, J.; HONDA, C.N.; KROHNE, S.G. et al. Effect of topical administration of $1 \%$ morphine sulfate solution on signs of pain and corneal wound healing in dogs. American Journal Veterinary Research. v.64, n.7, p.813-818, 2003.

TRESCOT, A.M.; DATTA, S.; LEE, M. et al. Opioid Pharmacology. Pain Physician. v.11, p.133-153, 2008.

WENK, H.N.; HONDA, C.N. Immunohistochemical localization of delta opioid receptors in peripheral tissues. J Comp Neurol. v.408, n.4, p.567-579, 1999.
WENK, H.N.; NANNENGA, M.N.; HONDA, C.N. Effect of morphine sulphate eye drops on hyperalgesia in the rat cornea. Pain. v. 105 , p. $455-465$, 2003.

WERNER, A.; BRAUN, M.; KIETZMANN, $M$. Isolation and cultivation of canine corneal cells for in vitro studies on the anti-inflammatory effects of dexamethasone. Veterinary Ophthalmology. v.11, n. 2, p.67-74, 2008a.

WERNER, A.; BRAUN, M.; REICHL, S. et al. Establishing and functional testing of a canine corneal construct. Veterinary Ophthalmology. v.11,n. 5, p.280-289, 2008b.

ZAGON, I.S.; SASSANI, J.W.; MCLAUGHLIN, P.J. Re-epithelization of the rat cornea is accelerated by blockade of opioid receptors. Brain Research. v.798, p. 254-260, 1998. 